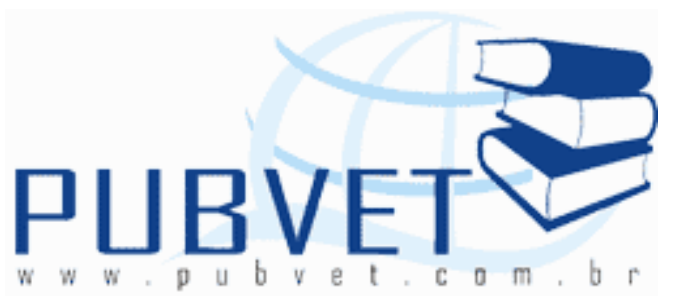

PUBVET, Publicações em Medicina Veterinária e Zootecnia.

\title{
Avaliação dos marcadores de prognóstico Ki-67, p53 no tumor mamário maligno de cadelas
}

Ana Carolina Trompieri-Silveira ${ }^{1}$, Geórgia Modé Magalhães ${ }^{2}$, Antonio Carlos Alessi $^{2}$

${ }^{1}$ Bolsista DCR - Departamento de Zootecnia - UFS

${ }^{2}$ Pós-Graduanda Patologia Animal - UNESP

${ }^{3}$ Professor titular -UNESP Jaboticabal

\section{Resumo}

Tendo em vista a elevada incidência das neoplasias mamárias nas cadelas, este trabalho teve como objetivo investigar os marcadores de prognóstico nos tumores malignos caninos. Para a realização deste estudo foram selecionadas 30 amostras de tumores mamários de cadelas. As amostras foram divididas em 3 grupos, de acordo com a classificação histopatológica sendo, carcinossarcoma, carcinoma sólido, carcinoma tubulopapilar. A avaliação dos marcadores de prognóstico Ki-67, p53, foi conduzida por imuno-histoquímica, utilizando-se a técnica estreptoavidina-biotina-peroxidase. Para o Ki-67 a diferença significativa foi vista entre o carcinoma sólido e carcinoma tubulopapilar. $O$ gene p53 apresentou diferença significativa $(P<0,05)$ entre a imunorreatividade do carcinossarcoma e do carcinoma sólido e tubulopapilar.

Palavras-chave: Neoplasia; tumor de mama; cadela; marcadores; prognóstico. 


\title{
Evaluation of the Ki-67, p53 in malignant mammary tumors in the bitch
}

\begin{abstract}
In view of the high incidence of mammary neoplasia in dogs, the aim of this study was to investigate the prognostic markers in the malignant mammary tumors of the female dog. For this, a sample of 30 mammary tumors was selected. The samples were divided into three groups according to histopathological classification: carcinosarcoma, solid carcinoma or tubulopapillary carcinoma. The Ki-67, p53, prognostic markers were evaluated by means of immunohistochemistry, using the streptavidin-biotin-peroxidase technique. For Ki-67, a significant difference was seen between solid and tubulopapillary carcinomas. The p53, a significant difference was seen between carcinosarcoma and solid anda tubulopapillary carcinomas.
\end{abstract}

Keywords: neoplasia; mammary tumors; dogs; markers; prognostic.

\section{INTRODUÇÃO}

Os tumores mamários são as neoplasias mais frequentes na fêmea canina e também na mulher (Moulton, 1990; Cotran et al., 2000). Aproximadamente metade dos tumores mamários caninos são malignos, entre 41 e 53\% (Misdorp et al., 1999; Rutteman et al., 2001), constituindo uma das principais causas de morte na cadela.

Informações prognósticas sobre o tumor mamário podem ser obtidas através do grau histológico, avaliação da proliferação celular (Ki-67) (Zacchetti et al., 2003; Yang et al., 2006), expressão de receptores hormonais (Nieto et al., 2000; Martín de las Mulas et al., 2005; Millanta et al., 2006) e expressão aberrante da proteína supressora de tumor P53 (Lee et al., 2004).

A detecção e quantificação das células em proliferação constituem parâmetros importantes no prognóstico de diferentes tumores, uma vez que a capacidade proliferativa tem sido importante na identificação de neoplasias, associada ao grau de malignidade (Sakai et al., 2002). 
Uma forma de conhecer o índice de proliferação celular é a determinação de proteínas específicas do ciclo celular, tal como Ki-67, cuja utilidade como fator prognóstico tem sido demonstrada no carcinoma mamário da mulher (Gasparini et al., 1994).

Existem também numerosos estudos focando a investigação do papel significativo do gene supressor de tumor p53, na formação de neoplasias humanas e caninas. As funções do p53 estão relacionadas às respostas aos constantes bombardeamentos genotóxicos que as células sofrem ao longo de suas vidas. A proteína p53 está diretamente relacionada ao bloqueio do ciclo celular, no caso de dano no DNA, apoptose ou diferenciação (Wu et al., 2006).

Acredita-se que mutações no gene p53 sejam as alterações mais comuns em tumores mamários caninos, além disso, estudos relacionados com tumores malignos em cães indicam que a mutação no p53 é associada com progresso do tumor (Mayr et al., 1998; Veldhoen et al., 1999).

Dessa forma, o objetivo deste estudo foi: avaliar a presença e quantificar a expressão dos indicadores de prognóstico Ki-67 e p53.

\section{MATERIAL E MÉTODOS}

As amostras tumorais que constituíram os grupos experimentais foram oriundas de cães fêmeas, de várias raças e idades, que foram encaminhadas para o Departamento de Patologia Veterinária da FCAV - UNESP - Jaboticabal - SP, nos anos de 2007 e 2008, para o diagnóstico histopatológico. Os espécimes classificados de acordo com Misdorp et al. (1999) como Carcinossarcoma, Carcinoma Sólido, Carcinoma Tubulopapilar, fizeram parte do presente trabalho. O número de casos selecionados para cada tumor foram $10(n=10)$, totalizando 30 animais.

Os marcadores de prognóstico utilizados foram índice de proliferação celular (Ki-67, clone MIB1 - DAKO A/S, Denmark) o qual é anticorpo monoclonal e o gene supressor de tumor ( $p-53$, NCL-p53-CM1 - Novocastra Laboratories), que é um anticorpo policlonal. 

prognóstico Ki-67, p53 no tumor mamário maligno de cadelas. PUBVET, Londrina, V. 6, N. 16, Ed. 203, Art. 1361, 2012.

As reações de imuno-histoquímica foram realizadas no Departamento de Patologia Veterinária da FCAV - UNESP - Jaboticabal - SP. Os tumores

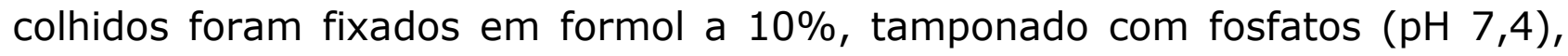
permanecendo nessa solução por um período máximo de 12 horas e depois foram processados para inclusão em parafina.

O método de imuno-histoquímica empregado foi o Complexo Estreptoavidina-Biotina Peroxidase ( $A B C)$. Resumidamente, os cortes de tecido (5 um) foram desparafinizados e reidratados. Na seqüência, foi realizado o bloqueio da peroxidase endógena (solução de $50 \mathrm{~mL}$ de metanol, $50 \mathrm{~mL}$ de água destilada e $2 \mathrm{~mL}$ de água oxigenada 30 volumes) por 30 minutos. Após essa etapa, os cortes foram lavados por três vezes em solução tamponada com fosfatos (PBS) 0,01 M (pH 7,2), por cinco minutos. A recuperação antigênica pelo calor foi feita de acordo com as indicações do fabricante. Após essa etapa, os sítios inespecíficos foram bloqueados com solução bloqueadora de reação inespecífica (protein block serum-free -catálogo $n^{0}$ X0909 - DAKO Corp.). Ato contínuo, os cortes foram recobertos com o anticorpo primário (Ki-67 - 1/50, p53 - 1/100) e, então, incubados a $4{ }^{\circ} \mathrm{C}$ por dezoito horas. Depois os cortes foram incubados com o anticorpo secundário biotinilado, (Kit DAKO LSAB + System cat. N. ${ }^{\circ}$ K0690) por trinta minutos, à temperatura ambiente. Em seguida, procedeu-se a incubação com o complexo streptoavidina-biotina, por trinta minutos (Kit DAKO LSAB + System cat. N. ${ }^{\circ}$ K0690), à temperatura ambiente, para detecção do produto da reação. Realizou-se a revelação com o cromógeno a base de diaminobenzidina (DAB), incubando por trinta segundos (cód. K3468- Dako Corporation, Carpinteria, USA).

Em seguida, a reação foi interrompida com a lavagem das preparações em água destilada, e feita a contracoloração com hematoxilina de Harris pura por um minuto, lavagem em água corrente e desidratação. Nesta última etapa, realizou-se passagens rápidas, em álcool etílico 850, 950, absoluto I e II, xilol I e II. As lâminas foram montadas com bálsamo do Canadá e observadas em microscópio de luz. 

prognóstico Ki-67, p53 no tumor mamário maligno de cadelas. PUBVET, Londrina, V. 6, N. 16, Ed. 203, Art. 1361, 2012.

Para se quantificar a freqüência da imunomarcação, foram aleatoriamente selecionados quatro campos por corte e, em cada campo, foi contado, na objetiva de 40x, um total de 100 células entre as marcadas e não marcadas. Desses campos foram extraídas porcentagens de células marcadas em relação ao total.

Os resultados foram submetidos ao programa Statistical Analysis System (SAS). A independência dos resultados (marcação para os anticorpos Ki-67, p53) com a classificação histopatológica e foi testada por meio de uma tabela de contingência 2X2 (Teste Qui-Quadrado).

\section{RESULTADOS E DISCUSSÃO}

Nos últimos anos, muito esforço tem sido feito para encontrar correlações entre estágio clínico e prognóstico clínico do tumor de mama canino (Benjamin et al., 1999). Essa correlação vem sendo analisada através da avaliação da proliferação celular (Ki-67) (Zacchetti et al., 2003; Yang et al., 2006), expressão de receptores hormonais (Nieto et al., 2000; Martín de lãs Mulas et al., 2005; Millanta et al., 2005) e expressão aberrante da proteína supressora p53 (Rungsipipat et al., 1999; Lee et al., 2004).

Os resultados encontrados, no presente trabalho, evidenciam a importância do estudo de marcadores celulares nas neoplasias mamárias pela técnica de imuno-histoquímica, pois foi possível determinar a presença, bem como quantificar a expressão dos receptores Ki-67 e p53.

O estudo de parâmetros que refletem as fases do ciclo celular de células neoplásicas tem mostrado ser útil na avaliação do comportamento biológico de tumores (O'reilly e Richards, 1992). Uma variedade de métodos têm sido introduzidos nessa área de pesquisa, mas somente alguns deles são aplicáveis em tecidos embebidos em parafina e fixados em formol. Devido a isso, a estimação da fração de crescimento foi analisada em nosso estudo por meio da demonstração imuno-histológica do então chamado índice de proliferação celular (Ki-67). 

prognóstico Ki-67, p53 no tumor mamário maligno de cadelas. PUBVET, Londrina, V. 6, N. 16, Ed. 203, Art. 1361, 2012.

Ki-67 é uma proteína não histona que expressa seu pico durante as fases G2/M do ciclo celular. Só aparece no núcleo de células que sabidamente estão ciclando ou seja, células quiescentes são consistentemente negativas (Gerdes e Zentgraf, 1998). Portanto, aparece em níveis elevados em tumores com alta proliferação celular (Figura 1A).

Ocorreu baixa detecção da proteína Ki-67 nos casos de carcinossarcoma $(11,7 \pm 6,02)$ e carcinoma tubulopapilar $(12,5 \pm 12,8)$. Todavia $18,8 \pm 11,25$ das células expressaram este antígeno no carcinoma sólido. Houve diferença significativa $(P<0,05)$ entre a imunorreatividade celular dos carcinomas sólidos e a dos outros dois tumores, levando-nos a pensar que o carcinoma sólido apresentava uma maior proliferação celular. A imunorreatividade em células não mitóticas era restrita ao núcleo, mas em células mitóticas a marcação se dava nos cromossomos, corroborando com os achado de Peña et al. (1998), observou-se também alguns nucléolos marcados.

A imunomarcação da p53 no presente trabalho, foi predominantemente nuclear (Figura 1B), havendo em algumas células imunorreatividade citoplasmática. Observou-se expressão da proteína p53 em todos os casos estudados. Provavelmente a utilização do anticorpo policlonal p53 conferiu maior expressão e menor especificidade, justificando a marcação de todos os tumores analisados, corroborando com os achados de Zuccari et al. (2005).

Presente nas células normais na forma "wild" ou não-mutante, o gene p53 tem a função de bloquear a divisão celular através de uma proteína por ele produzida, atuando como mediador da apoptose quando da ocorrência de alterações no genoma (Lowe et al., 1994). Quando este gene torna-se mutante, ocorre perda do controle do ciclo celular e, como conseqüência, pode ser observado distúrbios na indução da apoptose (May e May, 1999). 

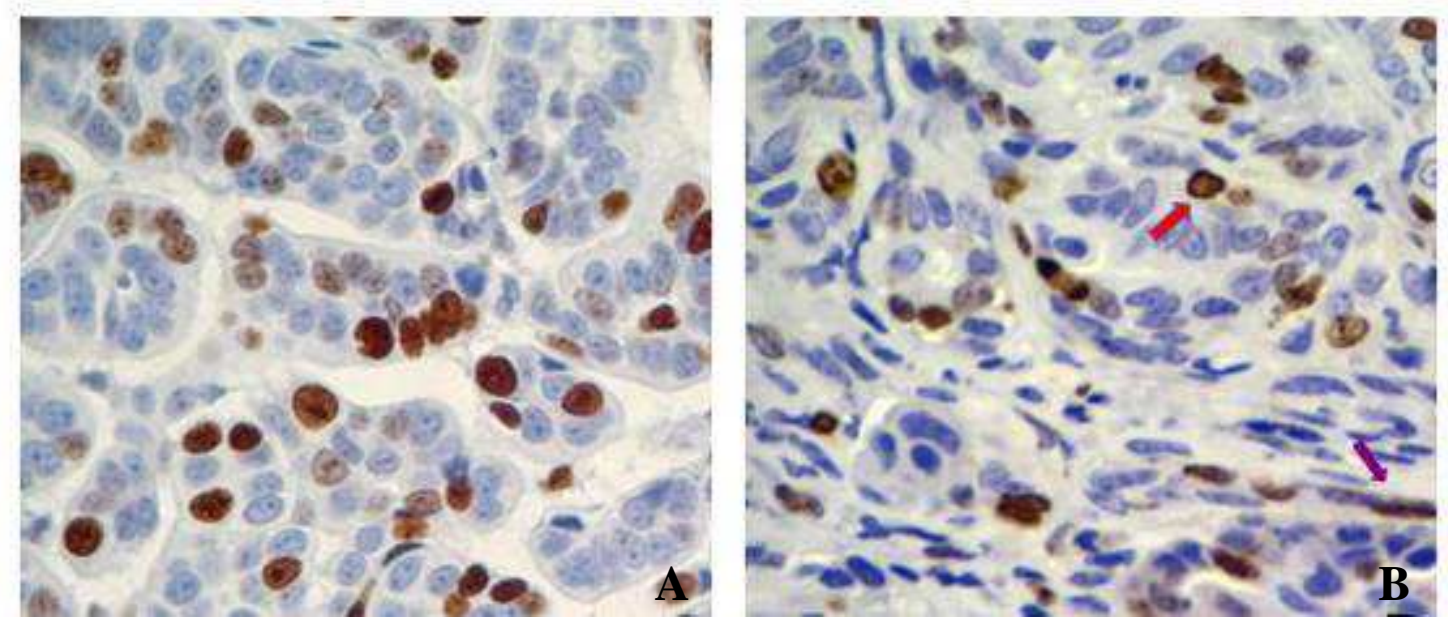

Figura 1 - Fotomicrografia de preparação imunoistoquímica em tumor mamário canino. A: Carcinoma Sólido, anticorpo anti-Ki-67. Notar coloração mais intensa em células em divisão. B: Carcinossarcoma, anticorpo anti-p53. Notar marcação em células epiteliais neoplásicas $(\Rightarrow)$ e também mioepiteliais $(\longrightarrow)$.

Observou-se baixa expressão $(6,4 \pm 2,92)$ nas células dos carcinossarcomas. No entanto, expressão para a p53 foi mais bem evidenciada nos carcinomas sólidos $(9,6 \pm 1,33)$ e nos carcinoma tubulopapilares $(8,8 \pm 1,68)$. Houve diferença significativa $(P<0,05)$ entre a imunorreatividade dos carcinossarcomas e a dos carcinomas sólidos e tubulopapilares, podendo-se sugerir que o carcinossarcoma apresentou menor concentração de mutações que os demais tumores. É interessante ressaltar, que se observou uma maior expressão da p53 nos mesmos tipos de tumores em que houve maior expressão do Ki-67, ou seja no carcinoma sólido e no tubulopapilar, o que leva a pensar em uma correlação da mutação celular com o índice de proliferação celular, corroborando com os achados de Lee et al. (2004). Como esses dois tumores são os tipos mais agressivos, talvez pudessem ser usados como marcadores de prognóstico.

Mutações no gene p53 têm sido associadas com o desenvolvimento de neoplasia mamária humana e canina, pacientes com câncer de mama com alterações do gene p53 são considerados de pior prognóstico. Entretanto, significado prognóstico de mutações no gene p53 em cães não é claro. No presente estudo, não foi possível relacionar a expressão da p53 com a 
TROMPIERI-SILVEIRA, A.C., MAGALHÃES, G.M. e ALESSI, A.C. Avaliação dos marcadores de prognóstico Ki-67, p53 no tumor mamário maligno de cadelas. PUBVET, Londrina, V. 6, N. 16, Ed. 203, Art. 1361, 2012.

sobrevida dos cães, devido à impossibilidade de acompanhamento dos animais.

\section{CONCLUSÃO}

Pode-se concluir que a imunomarcação de receptores p53 e Ki-67 nos tumores de mama malignos em cadela aumenta com o aumento da malignidade.

\section{AGRADECIMENTO}

À Fundação de Amparo à Pesquisa do Estado de São Paulo (FAPESP), pelo apoio financeiro (Processos 07/00971-5 e 06/00249-5).

Às técnicas de laboratório Maria I. Y. de Campos e Francisca A. Ardison pelo excelente trabalho na confecção de lâminas histológicas.

\section{REFERÊNCIAS}

BENJAMIN, S. A.; LEE, A. C.; SAUNDERS, W. J. Classification and behavior of canine mammary epithelial neoplasms based on life-span observations in beagles. Veterinary Pathology, $v$. 36, p. 423-436, 1999.

COTRAN, R. S.; KUMAR, V.; COLLINS, T. Robbins Patologia Estrutural e Funcional. 6. ed. Rio de Janeiro: Guanabara Koogan, 2000. p. 979-1002.

GASPARINI, G.; BORACCHI, P.; VERDEIRO, P.; BEVILACQUA, P. Cell kinetics in human breast câncer: comparison between the prognostic value of the cytofluorimetric $S$-phase fraction and that of the antibodies Ki-67 and PCNA antigens detected by immunocytochemistry.

International Journal of Cancer, v. 57, p. 822-829, 1994.

GERDES, J.; ZENTGRAF, H. Ki67/MIB1 immunostaining in tumor pathology. European Journal of Histology, v. 42, p.15, 1998.

LEE, C. H.; KIM, W. H.; LIM, J. H.; KANG, M. S.; KIM, D. Y.; KWEON, O. K. Mutation and overexpression of p53 as a prognostic factor in canine mammary tumors. Journal of Veterinary Science, v. 5, n. 1, p.63-69, 2004.

LOWE, S. W.; BODIS, S.; MACCLATCHEY, A. P53 status and the efficacy of cancer therapy in vivo. Science, n. 266, p. 807-810, 1994.

MARTÍN de LAS MULAS, J.; MILLÁN, Y.; DIOS, R. A prospective analysis of immunohistochemically determined estrogen receptor $\alpha$ and progesterone receptor expression and host ant tumor factors as predictors of disease-free period in mammary gland of the dog. Veterinary Pathology, v.42, p. 200-212, 2005.

MAY, P.; MAY, E. Twenty years of p53 research: structural and functional aspects of the p53 protein. Oncogene, v. 8, p. 7621-7636, 1999. 
MAYR, B.; DRESSLER, A.; REIFINGER, M.; FEIL, C. Cytogenetic alterations in eight mammary tumors and tumor-supressor gene p-53 mutation in one mammary tumor from dogs.

American Journal of Veterinary Research, v.59, p. 69-78, 1998.

MILLANTA, F.; CALANDRELLA, M.; BARI, G.; NICCOLINI, M.; VANNOZZI, I.; POLI, A.

Comparison of steroid receptor expression in normal, dysplastic, and neoplastic canine and feline mammary tissues. Research in Veterinary Science, v.79, p. 225-232, 2005.

MILLANTA, F.; CITI, S.; DELLA SANTA, D.; PORCIANI, M.; POLI, A. COX-2 expression in canine and feline invasive mammary carcinomas: correlation with clinicopathological features and prognostic molecular markers. Breast Cancer Research and Treatment, v. 98, n. 1, p. 115120, 2006.

MISDORP, W.; ELSE, R. W.; HELLMÉN, E. Histological classification of mammary tumors of the dog and the cat. Armed Forces Institute of Pathology, v. 7, n. 1, p.1-59, 1999.

MOULTON, J. E. Tumors of the mammary gland. In: Tumors in Domestic Animals. 3. ed. Los Angeles: University of California Press, 1990. Cap. 12, p. 518-552.

NIETO, A.; PENA, L.; PEREZ-ALENZA, M. D.; SANCHEZ, M. A.; FLORES, J. M.; CASTANO, M. Immunohistochemical detection of estrogen receptor alpha in canine mammary tumors: clinical and pathologic associations and prognostic significance. Veterinary Pathology, v. 37, p. 239$247,2000$.

O 'REILLY, S. M.; RICHARDS, M. A: Clinical aspects of assessing cell proliferation. In: Assessment of Cell Proliferation in Clinical Practice, ed. Hall PA, Levison DA, and Wright NA, pp. 63-79. Springer, London, UK, 1992.

PEÑA, L. L.; NIETO, A. I.; PÉREZ-ALENZA, D.; CUESTA, P.; CASTAÑO, M.

Immunohistochemical detection of Ki-67 and PCNA in canine mammary tumors: Relationship to clinical and pathologic variables. Journal of Veterinary Diagnostic Investigation, v. 10, n. 3, p. 237-346, 1998.

RUNGSIPIPAT, A.; TATEYAMA, S.; YAMAGUCHI, R.; UCHIDA, K.; MIYOSHI, N.; HAYASHI, T. Immunohistochemical analysis of c-yes and c-erbB-2 oncogene products and p53 tumor suppressor protein in canine mammary tumors. Journal of Veterinary Medical Science, $v$. 61, p. 27-32, 1999.

RUTTEMAN, G. R.; WITHROW, S. J.; MACEWEN, E. G. Tumors of the mammary gland. In: Small animal clinical oncology. 3 ed. Philadephia: Saunders., 2001, p. 455-467.

SAKAI, H.; NODA, A.; SHIRAI, N.; TIDAKA, T.; YANAI, T.; MASEGI, T. Proliferative Activity of Canine Mast Cell Tumors Evaluated by Bromodeoxyuridine Incorporation and Ki-67 Expression. Journal of Comparative Pathology, v. 127, n. 4, p. 233-238, 2002.

VELDHOEN, N.; WATTERSON, J.; BRASH, M.; MILNER, J. Identification of tumor-associated and germ line p53 mutations in canine mammary cancer. British Journal of Cancer, v. 81, p. 409-415, 1999.

YANG, W. Y.; LIU, C. H.; CHANG, C. J.; LEE, C. C.; CHANG, K. J.; LIN, C. T. Proliferative activity, apoptosis and expression of oestrogen receptor and $\mathrm{BCl}-2$ oncoprotein in canine mammary gland tumors. Journal of Comparative Pathology, v. 134, p. 70-79, 2006.

WU, H.; HAYASHI, T.; INOUE, M. Immunohistochemical expression of Mdm2 and p53 in canine cutaneous mast cell tumours. Journal of Veterinary Medicine - A Physiology, Pathology, Clinical Medicine, v. 53, n. 2, p. 65-68, 2006.

ZACCHETTI, A.; VAN GARDEREN, E.; TESKE, E.; NEDERBRAGT, H.; DIERENDONCK, J. H.; RUTTEMAN, G. R. Validation of the use of proliferation markers in canine neoplastic and nonneoplastic tissues: comparison of Ki-67 and proliferating cell nuclear antigen (PCNA) expression versus in vivo bromodeoxyuridine labeling by immunohistochemistry. Acta

Pathologica, microbiologica et Immunologica, v. 111, p. 430-438, 2003. 
ZUCCARI, D. A. P. C.; TERZIAN, A. C. B. ; PEREIRA, R. S.; PAVAM, M. V.; RUIZ, C. M.; UEIRO, F. A. R.; ANDRADE, J. C. A.; CORDEIRO, J. A. Avaliação imunohistoquímica do gene p53 nas neoplasias mamárias caninas. ARS Veterinária, v. 21, n. 3, p. 344-350, 2005. 